\title{
St. Gallen Consensus 2013: Optimizing and Personalizing Primary Curative Therapy of Breast Cancer Worldwide
}

\author{
Hans-Joerg Senn \\ Tumor and Breast Center ZeTuP and Foundation St. Gallen Oncology Conferences (SONK), St. Gallen, Switzerland
}

Every two years, in March of odd years, the professional elite of the clinical and research-oriented 'breast cancer world' from Europe, Asia, North- and South-America as well as Australia is called to the meanwhile traditional St. Gallen International Breast Cancer Conferences in Eastern Switzerland. In mid-March 2013 again, some 3,500 breast cancer specialists - surgeons, radio- and medical oncologists, gynaecologists, pathologists and basic researchers - assembled in St. Gallen, united by one single goal and perspective: to critically review the present state of the art in optimising and personalising primary curative therapy of early operable breast cancer, and to consequently re-analyse and update the recommendations of the St. Gallen 2013 International Treatment Consensus accordingly. Once more, a multi-disciplinary, highly competitive panel of 48 experts in the field from 22 countries and more than 15 leading breast cancer cooperative groups were ready to meet this difficult, but important challenge. It should be emphasized that the members of this distinguished international consensus panel were confronted with the more than 100 delicate, and partially controversial diagnostic and therapeutic questions, long before the terminal, open consensus session, which traditionally closes each St. Gallen Breast Cancer Conference since the third such international event in 1988. It is also important to state that from the beginning, the organizers of the St. Gallen Breast Cancer Conferences and the final consensus sessions have been paying special attention to the scientific independence and integrity of the invited moderators, speakers and panellists. All of them have to openly declare their possible institutional and financial relationships with industry and other institutions that could potentially influence their presentations and especially their voting interests during the consensus session.

While the final, commented version of the widely respected St. Gallen Breast Cancer Treatment Consensus 2013 is presently dealt with in various editorial correction rounds by the chairpersons and members of the consensus panel, the editors of BREAST CARE - part of whom are active panel members - have chosen to rapidly analyse and publish the presently available discussions and voting results of the recent St. Gallen consensus session 2013, in order to inform their journal's readership in a preliminary fashion, as not all were able to follow the recent consensus session in person.

Especially the voting results of the panel regarding the recommendations for loco-regional adjuvant therapies (indication and extent of axillary surgery and of adjuvant radiotherapy), but also more specific recommendations in regard to patient selection for additional adjuvant chemotherapy in oestrogen receptor-positive breast cancer patients on the basis of presently proliferating molecular screening tests were heavily debated by the consensus panel, and will most probably lead to detectable changes in the wording of the final consensus statement 2013. Meanwhile, the new molecularly defined breast cancer sub-entitites (luminal A, luminal B, basal like or triple-negative, etc.) have been firmly established in the vocabulary of present-day breast cancer treatment, influencing the clinical selection of most appropriate adjuvant therapies. Also the special aspects of optimal neo-adjuvant (or better pre-operative) treatments was thoroughly covered by the panel in various questions - a clinically visible treatment strategy of 'hope' and with a distinct future, regarding recent developments in multi-receptor blockade by the respective targeted agents. For the first time in its history, the panel also touched questions and problems of surveillance after breast cancer treatment.

The final wording of the St. Gallen International Breast Cancer Consensus Statement 2013 is presently in preparation and will be published as rapidly as possible online and then in paper in Annals of Oncology as well as thereafter also on the website of the Foundation SONK (St. Gallen Oncology Conferences): $w w w . o n c o c o n f e r e n c e s . c h$.

As a pre-view: The next (14th) St. Gallen International Breast Cancer Conference - for logistical reasons - will exceptionally take place March 18th-21st 2015 in Vienna/ Austria.

\section{KARGER \\ Fax +497614520714 \\ Information@Karger.com}

www.karger.com (c) 2013 S. Karger GmbH, Freiburg

1661-3791/13/0082-0101\$38.00/0

Accessible online at:

www.karger.com/brc
Prof. Dr. med. Hans-Jörg Senn, Co-Chai

St. Gallen International Breast Cancer Conferences

Scientific Director, Tumor and Breast Center ZeTuP

Rorschacherstrasse 150, 9006 St. Gallen, Switzerland

hansjoerg.senn@zetup.ch 